\title{
Benign prostatic hyperplasia: the best treatment
}

\author{
Many non-specific treatments, but an operation is best
}

Urology has been thrown into ferment by recent advances in pharmacological, ${ }^{12}$ hormonal, ${ }^{3}$ mechanical, ${ }^{45}$ and thermal techniques ${ }^{6}$ for either slowing the growth of the prostate or relieving obstruction caused by its enlargement. It has taken nearly 50 years for surgeons in Britain to accept that the prostate is best removed by transurethral resection compared with an open prostatectomy: it is not only more agreeable for the patient but also reduces the length of stay in hospital and appreciably reduces morbidity. The fact that a recent review has suggested that transurethral resection of the prostate may not be as good as urologists have claimed does not detract from the important advantages of this technique in treating benign prostatic hyperplasia.

But there are many other ways to treat the condition. Patients may have heard about treatment with balloon dilatation, ${ }^{4}$ urethral stents, ${ }^{5}$ hyperthermia, ${ }^{6}$ or several new drugs. ${ }^{1-3}$ Doctors have already been pressed for their opinion; clearly a path needs to be cut through this therapeutic jungle.

The prostate gland enlarges only in men with normal androgen production. ${ }^{8}$ The high concentration of dihydrotestosterone, the active metabolite of testosterone, in the prostate suggests that it must be linked to the growth of the gland. ${ }^{9}$ But the precise importance of androgens is uncertain, and they may permit rather than cause growth. Animal studies have shown that oestrogens and aging are also important. The development of hyperplasia is accelerated by oestrogen, which enhances the number of androgen receptors in the gland; this allows for growth mediated by androgens even during the declining androgen production of old age. ${ }^{10}$

Reducing androgen production by surgical castration leads to shrinkage of the prostate, but this treatment has little appeal because of the inevitable loss of libido. ${ }^{12}$ Similarly, medical castration with analogues of luteinising hormone releasing hormone reduces the volume of the prostate and improves urine flow in about half of patients but also causes loss of libido. ${ }^{13}$ Simply stopping the supply of testicular androgens thus has no place in managing benign prostatic hyperplasia. But blocking the conversion of testosterone to dihydrotestosterone (a reaction mediated by $5 \alpha$-reductase) has interesting potential, and encouraging results have already been shown experimentally. ${ }^{1+}$ Patients with the testicular feminisation syndrome have a genetic deficiency of $5 \alpha$-reductase which stops prostatic growth, but because testosterone concentrations are normal so is the patient's libido. ${ }^{15}$ Thus great interest has been shown in a specific $5 \alpha$-reductase inhibitor now on clinical trial. Preliminary results show that the concentration of dihydrotestosterone in the prostate is reduced by four fifths and that there are no other associated hormonal changes and no adverse side effects. $^{3}$ Measurement of the volume of the prostate by magnetic resonance imaging showed a $28 \%$ reduction, but the mean increase in peak urinary flow rate was a modest $3 \mathrm{ml} / \mathrm{s}$ (E Stoner, personal communication); this improvement in flow rate can scarcely be compared with the improvement after transurethral resection. Data from these studies usually describe treatment only up to six months; we need to learn whether the improvement continues.

Other methods of blocking the action of androgens have attracted interest for more than 20 years. Cyproterone, ${ }^{16}$ a powerful progestogen (SH 582), ${ }^{17}$ flutamide, ${ }^{18}$ and medroxyprogesterone $^{19}$ have all been studied, and none has found a useful place in managing benign prostatic hyperplasiawhich should add some caution to initial reports from any such studies. A different approach-blocking either the production or action of oestrogens - has not proved effective against experimental benign prostatic hyperplasia. ${ }^{20}$ Nevertheless, clinical studies of aromatase inhibitors are in progress in some European countries.

Another form of drug treatment has sought to influence the muscular tone of the prostate capsule and bladder neck. Caine et al showed that the tone of the musculature could be influenced by a postsynaptic $\alpha$ receptor antagonistphenoxybenzamine. ${ }^{21}$ This drug had undoubted beneficial effects, but the complications of dizziness and postural hypotension are important limitations. Alternative and more selective postjunctional $\alpha_{1}$ adrenoceptor antagonists-for example, prazosin, indoramin, and terazosin - have now been shown to improve symptoms in patients with benign prostatic hypertrophy. ${ }^{22-2+}$ But placebos also improve the symptoms of prostate enlargement and have been reported to improve urinary flow rates. ${ }^{25}$ Thus the least that is required before pronouncing on the value of new drugs for benign prostatic hyperplasia are data from well controlled clinical trials.

The places of balloon dilatation of the prostatic urethra, ${ }^{4}$ intraurethral stents, ${ }^{5}$ and hyperthermia ${ }^{6}$ in treating benign prostatic hyperplasia have yet to be determined. Stretching the prostate does not treat the cause, although the duration of effect is better than might be expected; there may be theoretical reasons why hyperthermia might work, but the results from controlled clinical trials are awaited.

We need to remember the variability of symptoms attributed to benign prostatic hypertrophy and the high placebo 
response before reaching any therapeutic conclusions. The most serious risk to the patient is either that the doctor will try new drugs or that the patient will insist on a new non-operative treatment. There are two other risks: firstly, the patient may not be checked for the complications of prostatic obstruction such as bladder decompensation, diverticula, stones, hydronephrosis, or even uraemia; and, secondly, without a tissue diagnosis automatically obtained at the time of an operative prostatectomy focal carcinoma in up to a fifth of patients may be missed.

The cost of managing patients with benign prostatic hyperplasia is large-yet neither basic research into this disease nor the economic implications has attracted much interest, especially in Britain. In the United States Glynn et al reported a $29 \%$ probability of a 40 year old man having a prostatectomy. ${ }^{26}$ The indications for prostatectomy for symptoms are imprecise; three quarters of men over 50 will have symptoms thought to be related to an enlarged prostate -yet there is much debate whether these symptoms are caused by bladder outflow obstruction. ${ }^{27}$ There is also a debate over when these symptoms and signs indicate the need for prostatectomy. ${ }^{28} 29$ So it is not surprising that there should be variations in the rates of prostatectomy both regionally and nationally, but some of the larger discrepancies require further study. As populations age and patient expectations increase the prospect of controlling symptoms in some of these patients should attract more interest, especially if it eases the operative workload.

Professor of Surgery,

Western General Hospital,

Edinburgh EH4 2XU

1 Kirby RS, Coppinger SWC, Corcoran MV, Chapple CR, Flannigan M, Milroy EJG. Prazosin in the treatment of prostatic obstruction. Br f Urol 1987;60:136-42.

2 Gower R, Wells P, United Kingdom Indoramin Study Group. Low dose indoramin, an alpha-adrenoreceptor antagonist, in the management of benign prostatic hypertrophy. Neurourology and Urodynamics 1988;7:216-7.

3 McConnell JD, Wilson JD, George FW, et al. An inhibitor of 5c-reductase, MK-906 suppresses prostatic dihydrotestosterone in men with benign prostatic hyperplasia. $\mathcal{F}$ Urol 1989:141:239a. Reddy PK, Wasserman N, Castaneda F, Castaneda-Luniga WR. Balloon dilatation of the prostate for the treatment of benign hyperplasia. Urol Clin North Am 1988;15:529-36.

5 Williams G, Jager R, McLoughlin L, et al. Use of stents for treating obstruction of urinary outflow in patients unfit for surgery. $\mathrm{Br}$ Med $\mathcal{J}$ 1989;298:1429.

6 Servadio C, Lindner A, Lev A, Leib Z, Siegel Y, Braf Z. Further observations on the effect of local hyperthermia on benign enlargement of the prostate. World fournal of Urology 1989;6:204-8.

Roos NP, Wennberg JE, Malenka DJ, et al. Mortality and reoperation after open and transurethral resection of the prostate for benign prostatic hyperplasia. N Englf Med 1989;320:1120-4.

8 Hunter J. Observations on certain parts of the animal economy. In: Palmer JF, ed. The complete Hunter J. Observations on certain parts of the animal economy. In: Palmer JF, ed. The
works of fohn Hunter. Vol 4. Philadelphia: Haswell, Barrington, and Haswell, 1841:68.

works of $\mathcal{f}$ ohn Hunter. Vol 4. Philadelphia: Haswell, Barrington, and Haswell, 1841:68.
9 Wilson JD. The pathogenesis of benign prostatic hyperplasia. Am $\mathcal{F}$ Med 1980;68:745-56.

9 Wilson JD. The pathogenesis of benign prostatic hyperplasia. Am f Med 1980;68:745-56.
10 Wilson JD. The testes and the prostate - a continuing relationship. N Engl f Med 1987;317:628-9.

10 Wilson JD. The testes and the prostate-a continuing relationship. N Engl I Med 1987;317
11 Cabot A'T. The question of castration for enlarged prostate. Ann Surg 1896;24:265-309.

12 Huggins C, Stevens RA. The effect of castration on benign hypertrophy of the prostate in man. f.Urol 1940;43:705-14.

13 Peters CA, Walsh PC. The effect of nafarelin acetate, a luteinizing-hormone-releasing hormone agonist, on benign prostatic hyperplasia. $N$ Engl 7 Med 1987;317:599-604.

14 Wenderoth UK, George FW, Wilson JD. The effect of $5 \alpha$-reductase inhibitor on androgen mediated growth of the dog prostate. Endocrinology 1983;113:569-73.

15 Walsh PC, Madden JD, Harrod MJ, Goldstein JL, MacDonald PC, Wilson JD. Familial incomplete male pseudohermaphroditism, type 2. N Engl f Med 1974;291:944-9.

16 Scott WW, Wade JC. Medical treatment of benign nodular prostatic hyperplasia with cyproterone acetate. F Urol 1969;101:81-5.

17 Aubrey DA, Khosla T. The effect of 17-alpha-hydroxy-19-norprogesterone caproate (SH 582) on benign prostatic hyperplasia. $\operatorname{Br} \mathcal{F}$ Surg 1971;58:648-52.

18 Caine M, Perlberg S, Gordon R. The treatment of benign prostatic hypertrophy with flutamide (SCH 13521): a placebo controlled study. $\mathcal{F}$ Urol 1975;114:564-8.

19 Geller J, Nelson CG, Albert JD, Pratt C. Effect of megestrol acetate on uroflow rates in patients with benign prostatic hypertrophy. Urology 1979;14:467-74.

20 Oesterling JE, Juniewicz PE, Walters JR, et al. Aromatase inhibition in the dog. II. Effect of growth, function and pathology of the prostate. F Urol 1988;139:832-9.

21 Caine $\mathrm{M}$, Perlberg S, Meretyk S. A placebo-controlled double-blind study of the effect of phenoxybenzamine in benign prostatic obstruction. Br $\mathcal{F}$ Urol 1978;50:551-4

22 Hedlund $\mathrm{H}$, Andersson K-E, Ek A. Effects of prazosin in patients with benign prostatic obstruction. F Urol 1983;130:275-8.

23 Lepor $H$, Baumann $M$, Shapiro $E$. The alpha adrenergic binding properties of terazosin in the human prostate adenoma and canine brain. $f$ Urol $1988 ; 140: 664-7$.

24 Dunzendorfer U: Clinical experience: symptomatic management of BPH with terazosin. Urology 1988;32(suppl):27-31.

25 Castro JE, Griffiths HJL, Edwards DE. A double blind controlled, clinical trial of spironolactone for benign prostatic hypertrophy. Br F Surg 1971;58:485-9.

26 Glynn RJ, Campion EW, Bouchard GR, Silbert JE. The development of benign prostatic hyperplasia among volunteers in the normative aging study. Am f Epidemiol 1985;121:78-82.

27 Abrams PH, Feneley RCL. The significance of symptoms associated with bladder outflow obstruction. Urol Int 1978;33:171-4.

28 Ball AJ, Feneley RCL, Abrams PH. The natural history of untreated prostatism. Br 7 Urol 1981;53:613-6.

29 Graversen PH, Gasser TC, Wasson JH, Hinman F, Bruskewitz RC. Controversies about indications for transurethral resection of the prostate. $\mathcal{F}$ Urol 1989;141:475-81.

\section{Treating patients with asthma who are dependent on systemic steroids}

\author{
The first step is to give inhaled steroids
}

Despite advances in treating asthma some patients still need continuous treatment with systemic corticosteroids. Such treatment has many side effects, including hyperglycaemia, hypertension, fluid retention, peptic ulceration, Cushing's syndrome, myopathy, increased susceptibility to infections, and behavioural disturbances. Osteoporosis seems to be particularly common, and a retrospective assessment of 128 patients aged 40 or above with asthma who are dependent on steroids noted vertebral or rib fractures in $11 \%$, but there were no fractures in 54 patients treated intermittently with systemic steroids.' The high incidence of side effects is often well known to patients, who may take the treatment irregularly or refuse it altogether. Measures to reduce the dose of steroids deserve close attention.

Any patient who requires maintenance treatment with oral corticosteroids should also have inhaled corticosteroids in order to minimise the systemic dose. But inhaled steroids are often not given. ${ }^{2}$ A dose of $800 \mu \mathrm{g}$ of inhaled beclomethasone allows for an appreciable reduction of the required dose of systemic steroids. ${ }^{34}$ Some asthmatic patients, however, still require oral treatment, and for them further treatment that spared the use of steroids would be valuable.

Alternatives to systemic steroids are usually drugs, but removing precipitating environmental factors and treating aggravating psychological causes may help. Various drugs have been proposed. Troleandomycin, a macrolide antibiotic, was described over 30 years ago because it prolonged the half life of methylprednisolone by slowing its elimination. But with doses of $1000 \mathrm{mg}$ daily most patients had steroid related side effects, ${ }^{5}$ and half had abnormalities in liver function. ${ }^{6}$ More recently daily doses of $250 \mathrm{mg}$ together with a rapid tapering of the dose of systemic steroids led to a two thirds reduction in overall steroid requirement; most patients were maintained on alternate day treatment and had no abnormalities in liver function. ${ }^{7}$ It is not clear whether troleandomycin has any other mechanism of action apart from slowing the elimination of methylprednisolone.

Parenteral gold has been given extensively for asthma in Japan for the past 15 years. It seems to exert an immunomodulatory effect on the $\mathrm{IgE}$ dependent system without compromising cell mediated immunity. Recently an oral gold preparation was given to asthmatic patients dependent on steroids in an open trial, and a reduction of a third in cumulative dosage of steroids was achieved. There was a correlation between the reduction in dose and responsiveness to methacholine. ${ }^{8}$ Side effects - particularly proteinuria, stomatitis, and diarrhoea-could prove troublesome.

Azathioprine in daily doses of $2 \mathrm{mg} / \mathrm{kg}$ body weight and $5 \mathrm{mg} / \mathrm{kg}$ has been studied in asthmatic patients dependent on steroids in short double blind crossover studies with no obvious benefit. ${ }^{9}$ And leucopenia, dyspepsia, and a threefold increase in the incidence of non-Hodgkin's lymphoma are all known complications.

Low dose methotrexate ( $15 \mathrm{mg}$ a week) was recently shown in a double blind crossover trial to reduce the requirement for systemic prednisolone by just over a third. ${ }^{10}$ This needs confirming in a longer trial with more patients. Methotrexate has an anti-inflammatory action in addition to suppressing the primary immune response. Unlike azathioprine, it does 